\title{
Paracorporeal lung assist device: An innovative surgical strategy for bridging to lung transplant in an infant with severe pulmonary hypertension caused by alveolar capillary dysplasia
}

\begin{abstract}
Umar S. Boston, MD, James Fehr, MD, ${ }^{\text {b,c }}$ Avihu Z. Gazit,
Alveolar capillary dysplasia is a frequently fatal congenital pulmonary disease during infancy. ${ }^{1}$ Lung transplantation (LT) is the only means of survival. We report the case of an infant with alveolar capillary dysplasia who subsequently had development of severe hemodynamic compromise as a result of refractory pulmonary hypertension $(\mathrm{PH})$ and was successfully bridged to LT with a paracorporeal lung assist device (PLAD) in a unique configuration.
\end{abstract}

\section{CLINICAL SUMMARY}

The patient was hospitalized at 2 months of age with hypoxemia. Echocardiography revealed systemic right ventricular pressures consistent with $\mathrm{PH}$, and chest computed tomographic scan demonstrated diffuse bilateral interstitial pulmonary fibrosis. Open lung biopsy yielded the diagnosis of alveolar capillary dysplasia with misalignment of the pulmonary veins. Subsequently, the child developed severe hemodynamic compromise from worsening $\mathrm{PH}$ despite maximum medical therapy, including prostacyclin and nitric oxide. The patient was therefore placed on venoarterial ECMO through the neck vessels. This rendered the patient ineligible for LT at our institution, because venoarterial ECMO is considered a contraindication in light of the poor outcomes of such patients. ${ }^{2}$ PLAD was considered to avoid the potential complications of ECMO, facilitate rehabilitation, and allow active listing for LT. In patients with severe $\mathrm{PH}$, PLAD requires central cannulation of the pulmonary artery (PA) and left atrium (LA), with an extracorporeal oxygenator interposed. ${ }^{3}$ The patient was supported on PLAD for 5 days before undergoing successful LT.

\section{DISCUSSION}

Incorporation of an oxygenator in a central configuration (PA to LA), whether it is the Novalung Surgical

\footnotetext{
From the Division of Cardiothoracic Surgery, ${ }^{a}$ Department of Surgery, the Division of Pediatric Anesthesiology, ${ }^{\mathrm{b}}$ and the Division of Critical Care, ${ }^{\mathrm{c}}$ Department of Pediatrics, St Louis Children's Hospital, Washington University in St Louis, St Louis, Mo.

Disclosures: Authors have nothing to disclose with regard to commercial support.

Received for publication May 14, 2013; revisions received May 28, 2013; accepted for publication June 11, 2013; available ahead of print July 22, 2013.

Address for reprints: Umar S. Boston, MD, Section of Pediatric Cardiothoracic Surgery, Division of Cardiothoracic Surgery, Department of Surgery, Washington University School of Medicine, Campus Box 8234, St Louis, Mo (E-mail: bostonu@ wudosis.wustl.edu).

J Thorac Cardiovasc Surg 2013;146:e42-3

0022-5223/\$36.00

Copyright (c) 2013 by The American Association for Thoracic Surgery

http://dx.doi.org/10.1016/j.jtcvs.2013.06.014
}

Lung Assist Device (Novalung GmbH, Heilbronn, Germany) or the Quadrox-iD Pediatric Oxygenator (MAQUET GmbH \& Co KG, Rastatt, Germany), allows adequate oxygenation and ventilation in patients with refractory $\mathrm{PH}$, provided there is normal biventricular function and no intracardiac shunt. Our decision to transition pediatric patients with refractory $\mathrm{PH}$ from venoarterial ECMO to PLAD was based on adult experience ${ }^{4}$ and lack of alternatives. PLAD provides right ventricular unloading, hemodynamic stability, and weaning from inotropes and pulmonary vasodilators. Furthermore, PLAD potentially allows extubation and physical rehabilitation before LT. Before this patient, we had transitioned 3 other children with refractory $\mathrm{PH}$ and severe hemodynamic compromise from venoarterial ECMO to PLAD. To date, this case represents the only patient who has been successfully bridged to LT with the PLAD. The previous major limitation was the inability to cannulate the LA with a durable cannula. The alternative-a DLP rightangle single-stage venous cannula (DLP, Medtronic, Inc, Grand Rapids, Mich)—was unstable and prone to thrombosis. Thromboembolism involving the LA cannula was the cause of mortality and morbidity in all of the previous patients.

We describe a novel configuration that allowed the use of Berlin cannulas (Berlin Heart AG, Berlin, Germany) in both the PA and LA positions. The oxygenator inflow used a 6-mm Berlin cannula anastomosed to the main PA. The oxygenator outflow was created by anastomosis of a 10$\mathrm{mm}$ polytetrafluoroethylene tube to the tip of a 6-mm Berlin cannula. The polytetrafluoroethylene tube was then anastomosed to an existing atrial septal defect through a right atriotomy such that oxygenated blood was channeled across the atrial septal defect from the right atrium to the LA (Figure 1).

The cannulation configuration described here has a number of potential advantages relative to direct cannulation of the LA. This configuration was designed to stabilize the intracardiac portion of the cannula and to improve the outflow dynamics by preventing obstruction of the small LA. Furthermore, the thromboembolic risk may be less because this configuration avoids a foreign body sitting within the LA. Five days of support with this configuration did not result in thromboembolic complications. A limitation of this novel cannulation strategy is that cardiopulmonary bypass has to be used. In addition, the heart has to be 


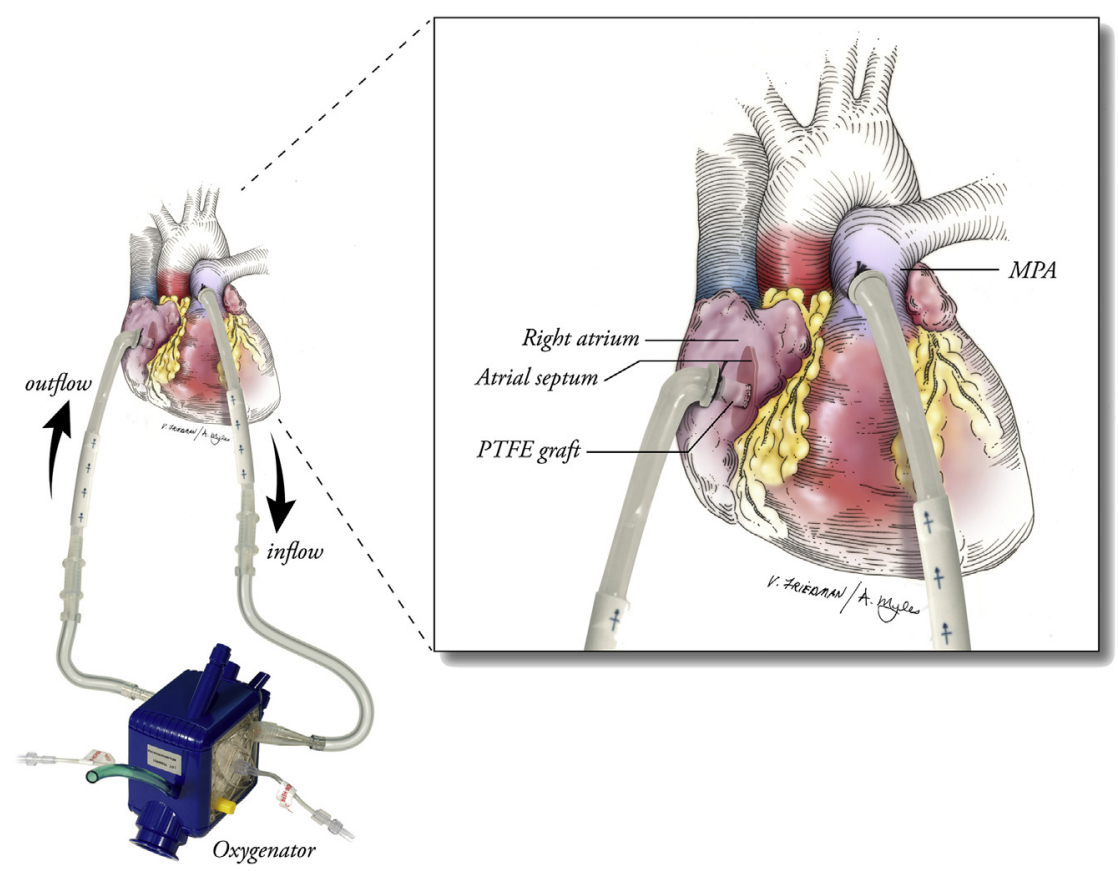

FIGURE 1. Paracorporeal lung assist device cannulation configuration. MPA, Main pulmonary artery; PTFE, polytetrafluoroethylene.

arrested or fibrillated for a short duration while the PTFE graft is anastomosed to the atrial septal defect. The impact of cardioplegic arrest was minimal, however, and the child separated from cardiopulmonary bypass with favorable hemodynamics and no inotropic support.

Pediatric patients bridged from venoarterial ECMO to LT have poor outcomes. This is the first case report in the literature of successfully bridging an infant with severe $\mathrm{PH}$ from venoarterial ECMO to LT by using a PLAD in a novel configuration. This case report illustrates an alternative form of durable mechanical pulmonary support as a bridge to LT for small pediatric patients.

\section{References}

1. Al-Hathlol K, Phillips S, Seshia MK, Casiro O, Alvaro RE, Rigatto H. Alveolar capillary dysplasia. Report of a case of prolonged life without extracorporeal membrane oxygenation (ECMO) and review of the literature. Early Hum Dev. 2000;57:85-94.

2. de Perrot M, Granton JT, McRae K, Cypel M, Pierre A, Waddell TK, et al. Impact of extracorporeal life support on outcome in patients with idiopathic pulmonary arterial hypertension awaiting lung transplantation. J Heart Lung Transplant. 2011;30:997-1002.

3. Gazit AZ, Sweet SC, Grady RM, Huddleston CB. First experience with a paracorporeal artificial lung in a small child with pulmonary hypertension. $J$ Thorac Cardiovasc Surg. 2011;141:e48-50.

4. Puri V, Epstein D, Raithel SC, Gandhi SK, Sweet SC, Faro A, et al. Extracorporeal membrane oxygenation in pediatric lung transplantation. $J$ Thorac Cardiovasc Surg. 2010;140:427-32. 